\title{
Role of Radical Prostatectomy for High-Risk Prostate Cancer
}

\author{
Dalsan You, In Gab Jeong, Choung-Soo Kim \\ Department of Urology, Asan Medical Center, University of Ulsan College of Medicine, Seoul, Korea
}

\begin{abstract}
High-risk localized prostate cancer traditionally includes patients with clinical T3 disease but also includes those with apparently localized disease but with adverse prognostic factors such as a Gleason score of 8 to 10, prostate-specific antigen of more than $20 \mathrm{ng} / \mathrm{ml}$, or extensive disease on biopsy. In the past, these patients were treated primarily with radiation therapy due to concerns that surgery was not likely to be curative and was associated with a high incidence of side-effects. In addition, the lack of randomized trials comparing curative treatments for high-risk prostate cancer makes treatment decisions in this patient population difficult. Several retrospective series have reported the long-term efficacy of radical prostatectomy monotherapy in a high-risk population, showing that the 5-year cancer-specific survival rate was more than $80 \%$ and the 5 -year biochemical recurrence-free survival rate was about $50 \%$. In addition, comparisons of different treatment options by means of nonrandomized trials have shown improved outcomes with surgery compared with radiation therapy or observation. Thus, there is renewed interest in radical prostatectomy as the primary treatment for patients with high-risk prostate cancer. Here, we reviewed the outcomes of radical prostatectomy, with or without neoadjuvant or adjuvant therapies, in high-risk patients and what is known about the choice and timing of adjuvant therapies.
\end{abstract}

Key Words: Prostatectomy; Prostatic neoplasms; Risk assessment

This is an Open Access article distributed under the terms of the Creative Commons Attribution Non-Commercial License (http://creativecommons.org/licenses/by-nc/3.0) which permits unrestricted non-commercial use, distribution, and reproduction in any medium, provided the original work is properly cited.

\author{
Article History: \\ received 10 August, 2010 \\ accepted 31 August, 2010
}

\author{
Corresponding Author: \\ Choung-Soo Kim \\ Department of Urology, Asan Medical \\ Center, University of Ulsan College of \\ Medicine, 388-1, Pungnap 2-dong, \\ Songpa-gu, Seoul 138-736, Korea \\ TEL: $+82-2-3010-3734$ \\ FAX: +82-2-477-8928 \\ E-mail: cskim@amc.seoul.kr
}

\section{INTRODUCTION}

The wide application of prostate-specific antigen (PSA) screening has led not only to a higher incidence of prostate cancer, but also to a profound stage migration [1]. With this remarkable stage migration, $91 \%$ of cases are being detected as clinically localized prostate cancer, whereas the proportion of metastatic disease at the time of diagnosis was just 4\% in the United States in 2009 [2]. Because the natural history of clinically localized prostate cancer varies from indolent disease to highly aggressive disease, the risk stratification of disease poses a significant challenge to the physician who treats patients with clinically localized prostate cancer. The potential aggressiveness of each tumor and the general health, life expectancy, and quality of life preferences of each patient must be assessed prior to selecting treatment. Although the optimal treatment for clinically localized prostate cancer has not been established because of a lack of randomized controlled trials, both radical pros- tatectomy $(\mathrm{RP})$ and radiation therapy $(\mathrm{RT})$ have excellent outcomes for low- and intermediate-risk disease. However, there is no consensus on the optimal treatment for high-risk localized prostate cancer, and much debate exists regarding the ideal treatment approach [3]. Most urologists recommend androgen-deprivation therapy (ADT) plus external- beam radiation therapy (EBRT), with only about $36 \%$ of high-risk patients initially treated with RP [4].

The aim of this article is to enable physicians to identify patients with high-risk localized prostate cancer and to review current data on the role of RP monotherapy for these patients. We have also reviewed current data about multi-modality therapies for patients with high-risk prostate cancer, including RP combined with neoadjuvant or adjuvant ADT and/or RT.

\section{DEFINITION OF HIGH-RISK PROSTATE CANCER}

Pretreatment risk stratification of newly diagnosed, clin- 
ically localized prostate cancer to predict the likelihood of treatment failure is essential for counseling and informed decision making. The risk of relapse following therapy has been estimated by using multiple definitions ranging from a single parameter, including clinical stage [5], biopsy Gleason score (GS) [6], and PSA [7], to a combination of variables [8] to scoring systems [9] or nomogram definition [10].

To date, however, there is no universally accepted definition of high-risk prostate cancer, and not all clinically high-risk prostate cancers defined by a single parameter are pathologically high-risk prostate cancers with a high likelihood of progression. Clinical staging by digital rectal examination failed to detect extraprostatic extension in $24 \%$ of patients [11] and over-staged organ-confined disease in $27 \%$ [5]. Poorly differentiated prostate cancer on biopsy is often downgraded in the final RP specimen [12]. Although high PSA concentration may be indicative of tumor burden, it may also be high due to benign prostatic hyperplasia or inflammation [13].

The most commonly accepted definition was proposed by D'Amico et al and defines high-risk prostate cancer as PSA more than $20 \mathrm{ng} / \mathrm{ml}$ or GS of 8 to 10 or clinical stage of at least T2c [8]. The proportion of patients presenting with high-risk prostate cancer by this definition decreased from $40.9 \%$ in 1989 to 1990 to $14.8 \%$ in 2001 to 2002 . The downward stage migration due to widespread PSA screening resulted in a significant shift in the determinants of prostate cancer risk stratification, with GS now more likely and PSA

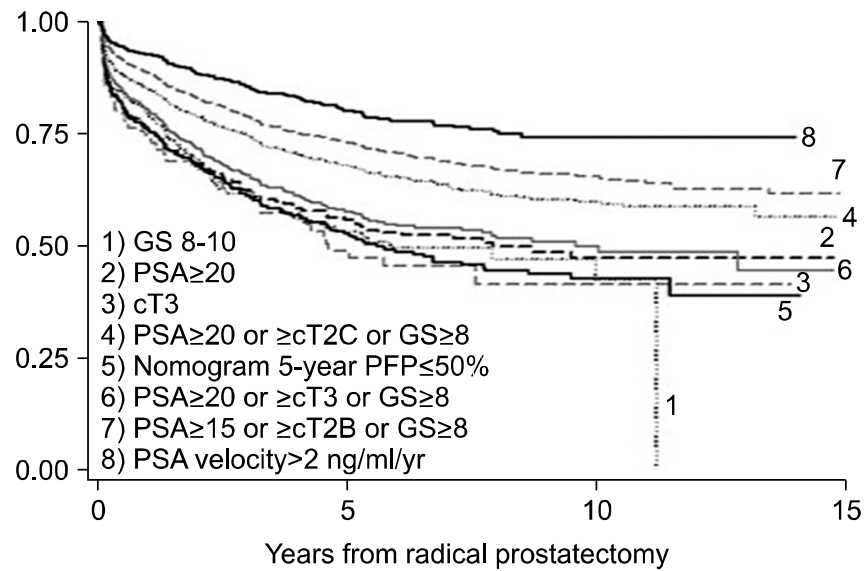

Number at risk:

$\begin{array}{lrrrrrrr}\text { 1) } & 274 & 110 & 51 & 28 & 11 & 2 & 1 \\ \text { 2) } & 275 & 146 & 106 & 66 & 30 & 14 & 4 \\ \text { 3) } & 144 & 63 & 34 & 13 & 6 & 2 & 1 \\ \text { 4) } & 957 & 557 & 375 & 213 & 112 & 36 & 10 \\ \text { 5) } & 391 & 198 & 124 & 75 & 35 & 11 & 3 \\ 6) & 605 & 295 & 179 & 100 & 42 & 16 & 4 \\ \text { 7) } 1,752 & 1,094 & 727 & 429 & 230 & 76 & 20 \\ \text { 8) } & 952 & 564 & 308 & 163 & 65 & 10 & 1\end{array}$

FiG. 1. Progression-free probability for patients with high-risk prostate cancer treated with radical prostatectomy alone by various definitions. Adapted with permission [16]. GS: Gleason score, PSA: prostate-specific antigen, PFP: progression-free probability. less likely to drive risk assignment [14]. The high-risk definition proposed by D'Amico et al is also used in the European Association of Urology (EAU) guidelines on prostate cancer [3]. The 2010 National Comprehensive Cancer Network (NCCN) guidelines define patients with clinically localized, high-risk disease as those with clinical stage T3a disease, GS 8 to 10 , or PSA more than $20 \mathrm{ng} / \mathrm{ml}$ and very- high-risk patients as those with clinical stage T3b-T4 disease [15].

The definition of high-risk prostate cancer influences the prediction of extraprostatic disease and treatment outcome. For example, a study of the relationships among various definitions of high-risk prostate cancer and the pathological characteristics of RP specimens and PSA relapse after $\mathrm{RP}$ found that, depending on its definition, $22-63 \%$ of patients had pathologically organ-confined disease, which is surgically curable with RP monotherapy or as part of a multimodal approach [16]. The risk of PSA relapse clearly varies related to the definition used. From $41 \%$ to $74 \%$ of the patients remained progression-free at 10 years after RP. The 10 -year progression-free probability rate ranged from $41 \%$ (the lowest) in 1992 TNM clinical T3 and 74\% (the highest) in the patients with high-risk cancer defined by a preoperative PSA velocity more than $2 \mathrm{ng} / \mathrm{ml} /$ year (Fig. 1).

\section{NATURAL HISTORY OF HIGH-RISK PROSTATE CANCER}

It is difficult to determine the natural history of high-risk prostate cancer. Because long-term survival rates are high in patients with prostate cancer, it is difficult to compare survival rates among risk groups. In addition, patients with high-risk prostate cancer are rarely allocated to active surveillance in contemporary cohorts. Several studies, however, can provide insights into the natural history of high-risk prostate cancer.

In a prospective cohort study before the PSA era, Johansson et al described the natural history of initially untreated prostate cancer [17]. In the clinically localized group (clinical stage of T2 or less), the corrected 15-year overall survival rate was similar in patients with deferred treatment and in patients who received initial treatment $(81 \%$ for both groups). Moreover, although prostate cancer accounted for $37 \%$ of all deaths, only $11 \%$ of patients with localized disease died due to prostate cancer. But the corrected 15-year overall survival was $57 \%$ in patients with locally advanced prostate cancer (clinical stage of T3-T4). Those authors concluded that patients with locally advanced disease need trials of aggressive therapy to improve their poor prognosis.

Reviews of two population-based cohorts of men with localized prostate cancer in the Connecticut Tumor Registry show the changes resulting from the introduction of widespread PSA testing $[18,19]$. The first cohort consisted of patients diagnosed with prostate cancer between 1971 and 1984 before the advent of PSA testing, whereas the second cohort consisted of men diagnosed with prostate cancer between 1990 and 1992, at the start of widespread PSA testing. 
The first cohort consisted of 767 men with clinically localized prostate cancer who underwent watchful waiting alone [18]. The 15-year cancer-specific mortality rate in men with GS 6 was $18 \%$ to $30 \%$, compared with a $25 \%$ to $59 \%$ risk of death from other causes. The mortality rates from prostate cancer were higher in patients with GS 7 (42\% to $70 \%)$ and GS 8-10 (60\% to $87 \%)$.

In the second population-based cohort, the authors examined the survival of men 75 years or younger who had clinically localized prostate cancer, comparing those treated with RP, EBRT, or observation [19]. Patients were stratified according to several methods, to control for both known and unknown confounding factors. The cancer-specific mortality rates in high-risk patients by the D'Amico classification, were 2.3- and 3.4-fold higher in the RT and observation groups, respectively, than in the RP group. The estimated 10-year cancer-specific survival rates in patients in the RP, EBRT, and observation groups were $90 \%, 80 \%$, and $70 \%$, respectively, for those with high-risk prostate cancer.

These results suggest that patients with high-risk prostate cancer are at significant risk of disease progression and cancer-specific deaths if left untreated and that RP may provide a survival advantage over EBRT or observation.

\section{RADIATION THERAPY WITH OR WITHOUT ANDROGEN DEPRIVATION THERAPY}

The RT dose for the management of low-risk prostate cancer is recommended to be at least $72 \mathrm{~Gy}$ by the EAU guidelines [3], and ranges from 70 to 79 Gy according to the 2010 NCCN guidelines [15]. The results of an M.D. Anderson Cancer Center trial showed that in patients with high-risk prostate cancer, dose escalation up to $78 \mathrm{~Gy}$ improves the results [20,21]. The 8-year biochemical recurrence-free rate was superior for the 78 Gy arm than for the 70 Gy arm (78\% vs. $59 \%, \mathrm{p}=0.004$ ), and the benefit was even greater in patients with an initial PSA more than $10 \mathrm{ng} / \mathrm{ml}$ (78\% vs. $39 \%$, $\mathrm{p}=0.001$ ). Moreover, the 8-year clinical failure rate was significantly lower in the 78 Gy than in the 70 Gy arm (7\% vs. $15 \%, \mathrm{p}=0.014$ ), although the incidence of grade 2 or higher gastrointestinal toxicity was twice as high in the 78 Gy arm (26\% vs. $13 \%)$ [21].

Because EBRT is insufficient to cover the tumor beyond the pelvis, the benefit of adjuvant ADT was prospectively evaluated $[22,23]$. In a randomized, prospective trial of patients with locally advanced prostate cancer, the 5-year clinical disease-free survival rate was significantly higher in patients treated with 70 Gy EBRT plus 3 years of ADT than in those treated with 70 Gy EBRT alone (74\% vs. $40 \%$, $\mathrm{p}=0.0001)$, as were the 5 -year overall survival rate (79\% vs. $62 \%, \mathrm{p}=0.0002)$ and 5-year cancer-specific survival rate (94\% vs. $79 \%, \mathrm{p}=0.0001$ ) [23].

Based on these findings, the $2010 \mathrm{NCCN}$ guidelines suggest that RT doses between 78 and $80+$ Gy improve PSAassessed disease control in patients with intermediate- or high-risk [15]. Moreover, these guidelines recommend patients with high-risk disease as candidates for pelvic lymph node irradiation and neoadjuvant/concomitant/adjuvant ADT for 2 to 3 years.

\section{RADICAL PROSTATECTOMY MONOTHERAPY}

There are two primary goals of treatment for patients with high-risk prostate cancer. The first is long-term cure, defined as undetectable PSA or biochemical recurrence-free survival; although, due to the slow progression of prostate cancer, alternate definitions of cure are encompassed in metastasis-free survival and cancer-specific survival. The second goal is local disease control. Locally progressive prostate cancer can cause recurrent hematuria, urinary retention, pain, and hydronephrosis, the relief of which requires palliative surgical intervention.

$\mathrm{RP}$ has been regarded as technically difficult in patients with high-risk prostate cancer and associated with high incidences of side effects, including frequent incontinence. A prospective study, however, found that the recovery and continence rates following RP were similar in patients with locally advanced and low-risk prostate cancer [24]. Table 1 summarizes the oncologic outcome in patients with highrisk prostate cancer treated with RP monotherapy.

A pooled analysis of 298 patients with clinical T3 disease, only $27(9 \%)$ with organ-confined disease, treated with RP monotherapy at several institutions in the United States and Europe found that the 5-year biochemical recurrencefree survival rates were $16 \%$ to $29 \%$ for patients with lowgrade tumors versus $11 \%$ for patients with high-grade tu-

TABLE 1. Reported series of radical prostatectomy monotherapy for high-risk prostate cancer

\begin{tabular}{|c|c|c|c|c|c|c|c|}
\hline & $\begin{array}{l}\text { No. of } \\
\text { patients }\end{array}$ & Definition & $\begin{array}{c}\text { Organ- } \\
\text { confined } \\
\text { disease }(\%)\end{array}$ & $\begin{array}{c}\text { 5-year } \\
\text { BCR-free } \\
\text { survival rate }(\%)\end{array}$ & $\begin{array}{c}\text { 8-year } \\
\text { BCR-free } \\
\text { survival rate }(\%)\end{array}$ & $\begin{array}{c}\text { 10-year } \\
\text { BCR-free } \\
\text { survival rate }(\%)\end{array}$ & $\begin{array}{l}\text { 10-year } \\
\text { CSS rate } \\
(\%)\end{array}$ \\
\hline Gerber et al, 1997 [25] & 298 & cT3 & 9 & 29 & & & 57 \\
\hline Van den Ouden et al, 1998 [26] & 83 & cT3 & 18 & 29 & & & 72 \\
\hline Van Poppel et al, 2000 [27] & 110 & cT3 & 15 & 60 & & & NA \\
\hline D’Amico et al, 2002 [28] & 429 & D'Amico & NA & & 33 & & NA \\
\hline Freedland et al, 2007 [29] & 56 & cТ3a & 9 & 62 & & 49 & 91 \\
\hline Loeb et al, 2009 [30] & 175 & D'Amico & 36 & & & 68 & 92 \\
\hline
\end{tabular}

BCR: biochemical recurrence, CSS: cancer-specific survival, NA: not assessed 
mors (GS 8-10) [25]. The 10-year cancer-specific and metastasis-free survival rates for all patients were $57 \%$ and $32 \%$, respectively, indicating that $\mathrm{RP}$ alone was unlikely to provide long-term survival benefits in men with high grade disease.

$\mathrm{RP}$ monotherapy in 83 patients with clinical T3 prostate cancer, 15 (18\%) with pathologically determined organ confined disease, found that the 5-year rate of PSA progression was $71 \%$ and the 5 - and 10 -year cancer-specific survival rates were $85 \%$ and $72 \%$, respectively [26]. These findings indicated that GS was a powerful predictor of recurrence and survival in patients with high PSA concentrations at diagnosis and failure to reach undetectable postoperative PSA.

A study of 110 men with clinical stage T3 prostate cancer found that $15 \%$ of these patients actually had organ-confined disease, illustrating a small but significant overstaging that can occur in clinical T3 patients [27]. Following RP monotherapy, the 5-year biochemical recurrence-free survival rate was $40 \%$ and was strongly influenced by clinical stage and preoperative PSA.

In a large, retrospective study including 2,635 patients treated with RP or RT in the PSA era, the initial rates of biochemical (PSA-free) survival in high-risk patients initially favored RT; however, the rates in the RP and RT groups were similar after 8 years (33\% vs. 40\%, respectively) [28].

An assessment of long-term outcomes of RP in 56 patients with clinical T3a disease, $91 \%$ with pathological T3 disease, found that the 15-year biochemical recurrence-free, metastasis-free, and cause-specific survival rates were $49 \%$, $73 \%$, and $84 \%$, respectively [29]. Among the 28 patients with PSA recurrence, a PSA doubling time $<9$ months was significantly associated with increased risk of prostate cancer deaths. These findings indicated that RP alone provided long-term cancer control in about half of these men and that the PSA doubling time at the time of recurrence is a useful determinant of risk of prostate cancer deaths among patients with PSA recurrence.

A study of outcomes in 175 high-risk patients treated mainly with RP monotherapy found that, at a median follow-up of 8 years, 29\% experienced biochemical progression, $3.4 \%$ had local recurrence, $13 \%$ developed metastatic disease, and 6\% died due to prostate cancer [30]. The 10-year biochemical recurrence-free, metastasis-free, and cancer-specific survival rates were $68 \%, 84 \%$, and $92 \%$, respectively.

Taken together, the results of all of these studies show that $49-68 \%$ of patients with locally advanced prostate cancer were shown to achieve prolonged disease-free survival with $\mathrm{RP}$ alone $[29,30]$. More refined risk assessments are needed to determine whether surgical intervention alone or in combination with other therapies is optimal in individual patients with locally advanced prostate cancer.

\section{MULTI-MODALITY THERAPY INCLUDING RADICAL PROSTATECTOMY}

Regardless of the definition of high-risk prostate cancer, a substantial proportion of these patients require a multimodality treatment approach that includes both local and systemic therapies. In recent years, several series of such multiple treatment approaches have been published, and $\mathrm{RP}$ has been shown to provide an excellent foundation for oncologic control of these patients. The 2010 NCCN guidelines recommend $\mathrm{RP}$ with pelvic lymph node dissection for selected patients with high-risk or very-high-risk prostate cancer without fixation to adjacent organs [15].

\section{Neoadjuvant hormone therapy}

The vast majority of patients will respond to initial hormonal therapy, showing a significant shrinkage in the extent of the palpable tumor and a drop in serum PSA concentration. For example, the SWOG 9109 trial reported 5-year outcomes in 55 patients with clinical T3-T4 prostate cancer treated with 4 months of neoadjuvant hormone therapy followed by RP [31]. Nearly all patients showed significant shrinkage of the palpable tumor, and PSA was undetectable in $55 \%$. RP was feasible in all 55 patients, with acceptable complications, with rectal injury occurring in only 1 patient. Approximately $80 \%$ of these patients became completely continent with no pads. Histological examination of the RP specimens revealed positive nodes in $19 \%$, seminal vesicle invasion in $30 \%$, and positive surgical margins in $30 \%$. Despite this worrisome pathology, PSA remained undetectable in $70 \%$ of these patients after 5 years.

Neoadjuvant hormonal therapy prior to RP was found to significantly reduce the proportion of patients with positive surgical margins (odds ratio [OR]: $0.34,95 \%$ confidence interval [CI]: $0.27-0.42, \mathrm{p}<0.00001)$ and to improve other pathological variables such as lymph node involvement, pathological staging, and organ-confined rates. In addition, there was a borderline significant reduction in disease recurrence rate (OR: 0.74, 95\% CI: 0.55-1.0, p=0.05) [32]. Neoadjuvant hormonal therapy, however, did not significantly increase overall and progression-free survival rates.

Despite the lack of absolute evidence of efficacy, many urologists use neoadjuvant hormonal therapy in patients with clinical T3 disease for two reasons. First, it may make a potentially difficult surgery technically easier, perhaps improving the likelihood of obtaining negative surgical margins. Second, it cannot hurt and may even enhance a patient's chance of long-term cure [33]. Nevertheless, neoadjuvant ADT for RP is strongly discouraged in the 2010 NCCN guidelines [15].

\section{Adjuvant radiation therapy}

Although it seems logical that RT should improve cure rates after $\mathrm{RP}$ for patients with adverse pathological features, nonrandomized studies showed no survival advantage despite improved local control [34]. Analysis of the efficacy of adjuvant $\mathrm{RT}$ in patients with undetectable PSA and salvage RT in patients with increasing PSA has shown that biochemical recurrence-free survival rate is maximal in patients with undetectable PSA after RP $[35,36]$. These find- 
ings highlight the importance of the early application of combined modality treatment, when the tumor burden is at its lowest value and the likelihood of multiple sites of metastases is reduced.

Two prospective, randomized controlled trials (EORTC 22911 and SWOG 8794) have assessed the effectiveness of adjuvant RT. In the EORTC 22911 trial, 1,005 patients with a positive surgical margin or pT3 disease were randomly assigned to adjuvant EBRT (60-65 Gy) or no adjuvant EBRT [37]. The 5-year biochemical progressionfree survival (74\% vs. 53\%) and clinical progression-free survival ( $85 \%$ vs. $8 \%$ ) were higher in patients receiving adjuvant EBRT, but there were no significant differences in 5-year metastasis-free survival, cancer-specific survival, and overall survival rates. In the SWOG 8,794 trial, 425 patients with high-risk localized prostate cancer were randomly assigned to adjuvant EBRT (60-65 Gy) or observation only [38]. The median PSA relapse-free survival (13.8 vs. 10.3 years) and recurrence-free survival (9.9 vs. 3.1 years) periods were greater in the EBRT group. At a median follow-up of 10.6 years, the cancer-specific mortality and overall survival rates were significantly greater in the adjuvant EBRT arm. The results of these two trials suggest that adjuvant EBRT immediately after RP improved biochemical recurrence-free survival and local control in patients with pathologically advanced prostate cancer who are at high risk of progression. However, the ability of adjuvant EBRT to enhance metastasis-free survival and overall survival is unclear.

\section{Salvage radiotherapy}

A large retrospective study of 501 patients treated with salvage RT showed that the 4-year progression-free rate was $45 \%$ [39]. Factors associated with poor response included preradiotherapy PSA more than $2 \mathrm{ng} / \mathrm{ml}$, GS 8 to 10 , PSA doubling time less than 10 months, negative tumor margins, and seminal vesicle invasion. Salvage EBRT can produce good responses in patients with preradiotherapy PSA is less than $1.0 \mathrm{ng} / \mathrm{ml}$, or it may be better to start salvage $\mathrm{RT}$ as soon as biochemical recurrence is indicated.

\section{Adjuvant hormone therapy}

The use of hormonal therapy in high-risk patients after RP set the stage for such investigations. A retrospective analysis of patients with regional lymph node-positive disease found that survival rates were improved in patients who underwent orchiectomy plus RP compared with those who underwent RP alone [40], although a second study showed contradictory results [41]. These findings indicated the need for prospective trials of hormonal therapy after RP in high-risk patients. In one trial, 100 patients were randomly assigned to receive either immediate hormone therapy or observation [42]. In 98 evaluable patients, assessed at a median follow-up of 7.1 years, early hormone therapy showed highly significant advantages, as shown by significantly increased cancer-specific, progression-free, and overall survival rates. Nevertheless, the inability of the study to reach its accrual goals and a lower than expected survival rate in the observation arm have raised concerns regarding whether hormone therapy should be a standard of care $[43,44]$.

The apparent survival advantage observed in patients treated with early and long-duration hormone therapy is reminiscent of the survival advantages observed in patients treated with EBRT plus hormone therapy [45]. Patients with lymph node-positive disease are best managed with adjuvant hormonal therapy. Messing et al demonstrated an improvement in biochemical recurrence-free survival (hazard ratio [HR]: 3.42, 95\% CI: 1.96-5.98), cancer-specific survival (HR: 4.09, 95\% CI: 1.76-9.49), and overall survival (HR: 1.84, 95\% CI: 1.01-3.35) with immediate hormonal therapy after RP compared with therapy at the time of metastasis [46]. Early adjuvant therapy based on improved risk assessments, both in patients with positive margins and those with positive lymph nodes, has been found to improve cure rates in patients in greatest need of cure.

\section{Multi-modality therapy: radical prostatectomy, radi-} ation therapy, hormonal therapy, and chemotherapy

Although EBRT with ADT for 2 to 3 years is recommended for patients with high-risk prostate cancer in the 2010 NCCN guidelines, the optimal treatment for these patients has not yet been defined. We need more refined randomized studies of RP with neoadjuvant or adjuvant ADT and/or RT. We are also lacking information on chemotherapy in the neoadjuvant or adjuvant setting. RP, however, seems to be one of the most important modes of treatment in multi-modal therapy, maximizing survival in patients with locally advanced prostate cancer.

\section{CONCLUSIONS}

We believe in the value of aggressive surgical therapy for men with high-risk prostate cancer for the following reasons. Compared with observation alone, RP monotherapy may provide a long-term cancer-specific survival advantage, similar to that of EBRT. RP is the only method currently available for accurate pathological staging, resulting in more accurate risk stratification and guiding the use of multi-modality therapy. Even in patients who fail surgery, RP allows the achievement of durable local control. More accurate stratification of the individual patient's risk for progression and likelihood of response to treatment is required. In addition, it is necessary to individualize the timing and type of adjuvant therapy.

\section{Conflicts of Interest}

The authors have nothing to disclose.

\section{REFERENCES}

1. Cookson MM. Prostate cancer: screening and early detection. Cancer Control 2001;8:133-40.

2. Jemal A, Siegel R, Ward E, Hao Y, Xu J, Thun MJ. Cancer statistics, 2009. CA Cancer J Clin 2009;59:225-49. 
3. Heidenreich A, Aus G, Bolla M, Joniau S, Matveev VB, Schmid $\mathrm{HP}$, et al. EAU guidelines on prostate cancer. Eur Urol 2008;53: 68-80.

4. Meng MV, Elkin EP, Latini DM, Duchane J, Carroll PR. Treatment of patients with high risk localized prostate cancer: results from cancer of the prostate strategic urological research endeavor (CaPSURE). J Urol 2005;173:1557-61.

5. Ward JF, Slezak JM, Blute ML, Bergstralh EJ, Zincke H. Radical prostatectomy for clinically advanced (cT3) prostate cancer since the advent of prostate-specific antigen testing: 15-year outcome. BJU Int 2005;95:751-6.

6. Donohue JF, Bianco FJ Jr, Kuroiwa K, Vickers AJ, Wheeler TM, Scardino PT, et al. Poorly differentiated prostate cancer treated with radical prostatectomy: long-term outcome and incidence of pathological downgrading. J Urol 2006;176:991-5.

7. Spahn M, Joniau S, Gontero P, Fieuws S, Marchioro G, Tombal $\mathrm{B}$, et al. Outcome predictors of radical prostatectomy in patients with prostate-specific antigen greater than $20 \mathrm{ng} / \mathrm{ml}$ : a european multi-institutional study of 712 patients. Eur Urol 2010;Epub ahead of print

8. D'Amico AV, Whittington R, Malkowicz SB, Schultz D, Blank K, Broderick GA, et al. Biochemical outcome after radical prostatectomy, external beam radiation therapy, or interstitial radiation therapy for clinically localized prostate cancer. JAMA 1998;280: 969-74.

9. Cooperberg MR, Pasta DJ, Elkin EP, Litwin MS, Latini DM, Du Chane J, et al. The University of California, San Francisco Cancer of the Prostate Risk Assessment score: a straightforward and reliable preoperative predictor of disease recurrence after radical prostatectomy. J Urol 2005;173:1938-42.

10. Eastham JA, Kelly WK, Grossfeld GD, Small EJ. Cancer and Leukemia Group B (CALGB) 90203: a randomized phase 3 study of radical prostatectomy alone versus estramustine and docetaxel before radical prostatectomy for patients with high-risk localized disease. Urology 2003;62(Suppl 1):55-62.

11. Grossfeld GD, Chang JJ, Broering JM, Li YP, Lubeck DP, Flanders SC, et al. Under staging and under grading in a contemporary series of patients undergoing radical prostatectomy: results from the Cancer of the Prostate Strategic Urologic Research Endeavor database. J Urol 2001;165:851-6.

12. Fine SW, Epstein JI. A contemporary study correlating prostate needle biopsy and radical prostatectomy Gleason score. J Urol 2008; 179:1335-8

13. Eastham JA, Riedel E, Scardino PT, Shike M, Fleisher M, Schatzkin A, et al. Variation of serum prostate-specific antigen levels: an evaluation of year-to-year fluctuations. JAMA 2003; 289:2695-700.

14. Cooperberg MR, Lubeck DP, Mehta SS, Carroll PR. Time trends in clinical risk stratification for prostate cancer: implications for outcomes (data from CaPSURE). J Urol 2003;170:S21-5.

15. Mohler J, Bahnson RR, Boston B, Busby JE, D'Amico A, Eastham JA, et al. NCCN clinical practice guidelines in oncology: prostate cancer. J Natl Compr Canc Netw 2010;8:162-200.

16. Yossepowitch O, Eggener SE, Bianco FJ Jr, Carver BS, Serio A, Scardino PT, et al. Radical prostatectomy for clinically localized, high risk prostate cancer: critical analysis of risk assessment methods. J Urol 2007;178:493-9.

17. Johansson JE, Holmberg L, Johansson S, Bergström R, Adami HO. Fifteen-year survival in prostate cancer. A prospective, population-based study in Sweden. JAMA 1997;277:467-71.

18. Albertsen PC, Hanley JA, Gleason DF, Barry MJ. Competing risk analysis of men aged 55-74 years at diagnosis managed con- servatively for clinically localized prostate cancer. JAMA 1998; 280:975-80.

19. Albertsen PC, Hanley JA, Penson DF, Barrows G, Fine J. 13-year outcomes following treatment for clinically localized prostate cancer in a population based cohort. J Urol 2007;177:932-6.

20. Pollack A, Zagars GK, Smith LG, Lee JJ, von Eschenbach AC, Antolak JA, et al. Preliminary results of a randomized radiotherapy dose-escalation study comparing 70 Gy with 78 Gy for prostate cancer. J Clin Oncol 2000;18:3904-11.

21. Kuban DA, Tucker SL, Dong L, Starkschall G, Huang EH, Cheung MR, et al. Long-term results of the M. D. Anderson randomized dose-escalation trial for prostate cancer. Int J Radiat Oncol Biol Phys 2008;70:67-74.

22. Bolla M, Gonzalez D, Warde P, Dubois JB, Mirimanoff RO, Storme $\mathrm{G}$, et al. Improved survival in patients with locally advanced prostate cancer treated with radiotherapy and goserelin. N Engl J Med 1997;337:295-300.

23. Bolla M, Collette L, Blank L, Warde P, Dubois JB, Mirimanoff RO, et al. Long-term results with immediate androgen suppression and external irradiation in patients with locally advanced prostate cancer (an EORTC study): a phase III randomised trial. Lancet 2002;360:103-6.

24. Berglund RK, Jones JS, Ulchaker JC, Fergany A, Gill I, Kaouk $\mathrm{J}$, et al. Radical prostatectomy as primary treatment modality for locally advanced prostate cancer: a prospective analysis. Urology 2006;67:1253-6.

25. Gerber GS, Thisted RA, Chodak GW, Schroder FH, Frohmuller HG, Scardino PT, et al. Results of radical prostatectomy in men with locally advanced prostate cancer: multi-institutional pooled analysis. Eur Urol 1997;32:385-90.

26. van den Ouden D, Hop WC, Schröder FH. Progression in and survival of patients with locally advanced prostate cancer (T3) treated with radical prostatectomy as monotherapy. J Urol 1998;160: 1392-7.

27. Van Poppel H, Goethuys H, Callewaert P, Vanuytsel L, Van de Voorde W, Baert L. Radical prostatectomy can provide a cure for well-selected clinical stage T3 prostate cancer. Eur Urol 2000;38: 372-9.

28. D'Amico AV, Whittington R, Malkowicz SB, Cote K, Loffredo M, Schultz D, et al. Biochemical outcome after radical prostatectomy or external beam radiation therapy for patients with clinically localized prostate carcinoma in the prostate specific antigen era. Cancer 2002;95:281-6.

29. Freedland SJ, Partin AW, Humphreys EB, Mangold LA, Walsh PC. Radical prostatectomy for clinical stage T3a disease. Cancer 2007;109:1273-8.

30. Loeb S, Schaeffer EM, Trock BJ, Epstein JI, Humphreys EB, Walsh PC. What are the outcomes of radical prostatectomy for high-risk prostate cancer? Urology 2009;Epub ahead of print

31. Powell IJ, Tangen CM, Miller GJ, Lowe BA, Haas G, Carroll PR, et al. Neoadjuvant therapy before radical prostatectomy for clinical T3/T4 carcinoma of the prostate: 5-year followup, Phase II Southwest Oncology Group Study 9109. J Urol 2002;168:2016-9.

32. Kumar S, Shelley M, Harrison C, Coles B, Wilt TJ, Mason MD. Neo-adjuvant and adjuvant hormone therapy for localised and locally advanced prostate cancer. Cochrane Database Syst Rev 2006;4:CD006019.

33. Skinner EC, Glode LM. High-risk localized prostate cancer: primary surgery and adjuvant therapy. Urol Oncol 2003;21:219-27.

34. Anscher MS, Robertson CN, Prosnitz LR. Adjuvant radiotherapy for pathologic stage T3/4 adenocarcinoma of the prostate: ten-year update. Int J Radiat Oncol Biol Phys 1995;33:37-43. 
35. Kalapurakal JA, Huang CF, Neriamparampil MM, Small WJ Jr, Pins MR, Mittal BB, et al. Biochemical disease-free survival following adjuvant and salvage irradiation after radical prostatectomy. Int J Radiat Oncol Biol Phys 2002;54:1047-54.

36. Catton C, Gospodarowicz M, Warde P, Panzarella T, Catton P, McLean M, et al. Adjuvant and salvage radiation therapy after radical prostatectomy for adenocarcinoma of the prostate. Radiother Oncol 2001;59:51-60.

37. Bolla M, van Poppel H, Collette L, van Cangh P, Vekemans K, Da Pozzo L, et al. Postoperative radiotherapy after radical prostatectomy: a randomised controlled trial (EORTC trial 22911). Lancet 2005;366:572-8.

38. Thompson IM Jr, Tangen CM, Paradelo J, Lucia MS, Miller G, Troyer D, et al. Adjuvant radiotherapy for pathologically advanced prostate cancer: a randomized clinical trial. JAMA 2006; 296:2329-35.

39. Stephenson AJ, Scardino PT, Kattan MW, Pisansky TM, Slawin $\mathrm{KM}$, Klein EA, et al. Predicting the outcome of salvage radiation therapy for recurrent prostate cancer after radical prostatectomy. J Clin Oncol 2007;25:2035-41.

40. Myers RP, Larson-Keller JJ, Bergstralh EJ, Zincke H, Oesterling JE, Lieber MM. Hormonal treatment at time of radical retropubic prostatectomy for stage D1 prostate cancer: results of long-term followup. J Urol 1992;147:910-5.

41. Schmeller N, Lubos W. Early endocrine therapy versus radical prostatectomy combined with early endocrine therapy for stage D1 prostate cancer. Br J Urol 1997;79:226-34.

42. Messing EM, Manola J, Sarosdy M, Wilding G, Crawford ED, Trump D. Immediate hormonal therapy compared with observation after radical prostatectomy and pelvic lymphadenectomy in men with node-positive prostate cancer. N Engl J Med 1999;341: 1781-8.

43. Eisenberger MA, Walsh PC. Early androgen deprivation for prostate cancer? N Engl J Med 1999;341:1837-8.

44. Swanson GP. Early hormonal therapy in prostate cancer. N Engl J Med 2000;342:1215-6.

45. Verhagen PC, Schröder FH, Collette L, Bangma CH. Does local treatment of the prostate in advanced and/or lymph node metastatic disease improve efficacy of androgen-deprivation therapy? A systematic review. Eur Urol 2010;Epub ahead of print

46. Messing EM, Manola J, Yao J, Kiernan M, Crawford D, Wilding $\mathrm{G}$, et al. Immediate versus deferred androgen deprivation treatment in patients with node-positive prostate cancer after radical prostatectomy and pelvic lymphadenectomy. Lancet Oncol 2006; 7:472-9. 